\title{
Optimal Placement of Fault Passage Indicators in Distribution Networks using Genetic Algorithms
}

\author{
Abdelmadjid RECIOUI*, Mounir MERDJ, Anouar KAMLI \\ Laboratory of Signals and Systems, Institute of Electrical and Electronic Engineering, University \\ M'hamedBougara of Boumerdes, Avenue de l'indépendance, 35000, Algeria. \\ *arecioui@univ-boumerdes.dz
}

\begin{abstract}
Fault Passage Indicators (FPIs); also named Faulted Circuit Indicators (FCls), have been under development for the last 70 years including new capabilities to satisfy the needs of the distribution network operators. In order to improve system stability, these devices can be deployed along the feeder to reduce, or even eliminate, the uncertainty about the fault location. The number and location of FPIs affects the network reliability that can lead to extra charge on the distribution companies as well as the consumers. In this work, the optimal number and location of fault passage indicators in Power Distribution Networks (PDN) are determined. The problem is cast as an optimization task with a special economical combined objective function and solved using the genetic algorithms. The work has been tested on the two case studies, IEEE 9 bus and IEEE33 bus systems.
\end{abstract}

Keywords: Fault Passage Indicators, placement, distribution systems, optimization, genetic algorithms

\section{INTRODUCTION}

A power system is the largest network in earth with components converting non electrical energy continuously into the electrical form and transporting the electrical energy from generating sources to the loads/users. The main function of an electricity network is to transport energy from production centers to consumers. The provision of electricity, with regard to safety and availability, is a key point in the management of electricity grids. This is particularly true for distribution networks, the link between transmission and distribution networks and consumers. The management of such networks is complex because of their architecture, the small amount of data available and the various disruptions that may occur [1].

Failure in the power system distribution and transmission is unavoidable event due to number of undesirable nature accidents or human-errors (lightings, wind damage, ice loading, tree falling, bird shorting, vehicles hitting, people contacting, digging into underground cable.......), for that Power companies are in immense pressure to reduce outage time for customers and increase reliability of the system which means making the protection of the system better as it can be [2].The detection and localization of faults is therefore an increasingly important component for this management. In power grids, there are several types of faults (polyphase or single-phase). When these faults occur, operators must be aware of them, isolate and repair them as quickly as possible to satisfy customers. These actions constitute the detection and localization of faults in power grids [3-6].

To carry out fault detection and localization in distribution networks, it is possible to use Fault Passage Indicators (FPIs) also called as, faulted circuit indicator $(\mathrm{FCl})$. Such devices have been widely used in the distribution network to realize fast fault localization. These devices detect the presence of fault and possibly its direction by providing indications locally or to the remote control system. With these signals, operators can determine which part of the system is failing in order to quickly replenish the healthy parts of the system.By placing these devices at suitable locations in a distribution network, it is possible to accelerate the process of locating the fault, which in this case is between the last indicator that detected the passage of fault current and the first following that did not. It is also reasonable to add FPIs in networks with FLs already installed, which helps improving the overall accuracy of fault locating. However, there are significant costs related to installation of FPIs, which can cancel the profit from increased reliability. Thus, the main task is to determine the optimal number and positions of FPls for a given network, which will result in satisfactory ratio between installation costs and increased reliability [7].

It is neither economically sound nor necessary to install an FPI at each line segment of a wide-area distribution system. With so many line segments of a feeder in the power distribution system, the placement of FPIs becomes a very difficult and tedious 
problem to be solved by conventional optimization techniques because of the voluminous combinations to be examined. With the installation of FPIs in the distribution system, the reliability indices of customer service zones can therefore be evaluated according to the installation locations of Fls. As a result, the problem of optimal $\mathrm{FCl}$ placement (OFP) is concerned with where and how many FPls should be implemented in the distribution systems to heighten reliability at a minimum number of FPIs. There have been many optimization techniques to solve many engineering problems [8-11]. For large system applications, in order to reduce the search space in finding the optimum FPI locations, a sensitivity analysis is first conducted to find better candidate locations for FPI placement. Optimization algorithm is then designed and used to solve the optimum FPI placement problem.

Various papers have been published in the field of FPI placement in distribution networks. Several heuristic approaches such as simulated annealing [12], ant colony [13], immune algorithm [14], and particle swarm [15]-[16] have been already used to handle the placement problem. In [16], the authors considered a multi objective solution to minimize the number of installed switches and interrupted customers cost. In [17]-[18], decomposition and value based approaches were employed to solve the problem. Additionally, [19] proposed an algorithm to minimize loss as well as interrupted loads following a fault event. Apart from the above reviewed researches, the authors in [20] developed a mixed integer programming (MIP) model which ensures optimality of the solution. Also, in [21], authors developed a multistage MIP-based method to deal with the budget limitation of investors. In addition, the effect of switch malfunction probability on SS placement problem was considered in [22][23].Switch placement considering financial risk induced by uncertainties was studied in placement of FPI as a component of smart grids has fascinated many researchers. At the first FPI is presented in [24] but this paper did not present any special method for finding number and position of FPIs. In continue different methods are presented for solving it such as GA (Genetic Algorithm), CBGA (ChuBeasley Genetic Algorithm) and IMA (Immune Algorithm). GA method, which is presented in [25], is used for solving the OFP problem. It finds the optimal place of FPls. Ref [26] analyzed the effect of FPls on reliability indices of PDN and the presented method in [26] is tested on real Iranian PDN.CBGA is used for optimal FPI location in PDN [7].
The main objective of this work is to formulate the FPI placement problem as an optimization task. The purpose is to achieve the technoeconomic balance, by obtaining maximum improvement of the reliability indices while using the minimum number of FPIs in addition of using an optimization algorithm for FPI placement which has a well-known global convergence capability.

\section{BACKGROUND}

\section{Fault Passage Indicators}

A fault passage indicator is a device which provides visual and remote indication of a fault on the electric power system. FPI, also called, faulted circuit indicator $(\mathrm{FCl})$, is a device used in electric power distribution networks for automatic detection and identification of fault location in order to reduce the outage time. Distribution Network Operators (DNO) have been using Fault Passage Indicators (FPI) in Medium Voltage grids as a key element to improve the reliability. These devices have proved to reduce the total outage time by guiding the locating crew straight to the faulted cable section [10]. This time reduction is translated in terms of better SAIDI (System Average Interruption Duration Index) and CAIDI (Customer Average Interruption Duration Index) indexes and also a reduction of the Energy Not Supplied (ENS) [27].

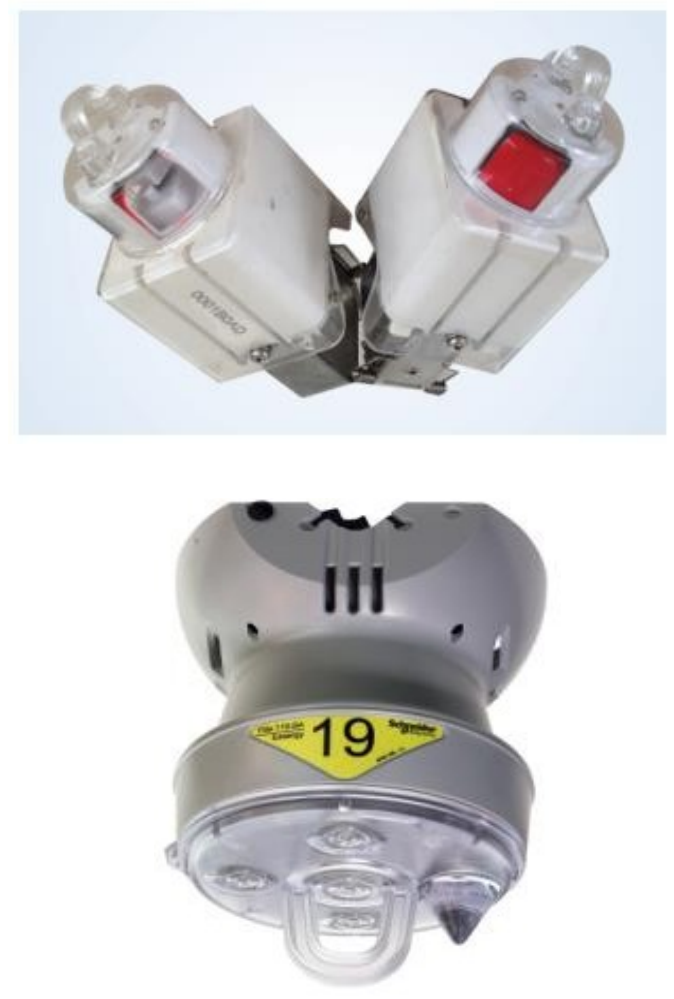

Fig. 1 Fault passage indicators 


\section{FPI locating system components}

Locating the fault in distribution lines requires more than FPI hence, other components have been added to get better results such as:

\section{a. Communication tool:}

A communication module transmits the information from the remote FPI directly to the operator or control room system responsible for network management through a communication gateway (Data Concentrator Unit).

\section{b. Communication gateway:}

It is mostly a cellular communication module installed nearby for onward transmission to SCADA system at the control center through a suitable communication channel via GSM/2G/3G/4G/4G cellular networks.

Using this system, the utility acquires information regarding the section of the line having the fault. This identification helps eliminate the patrolling of entire line for finding the fault, ultimately reducing restoration time.

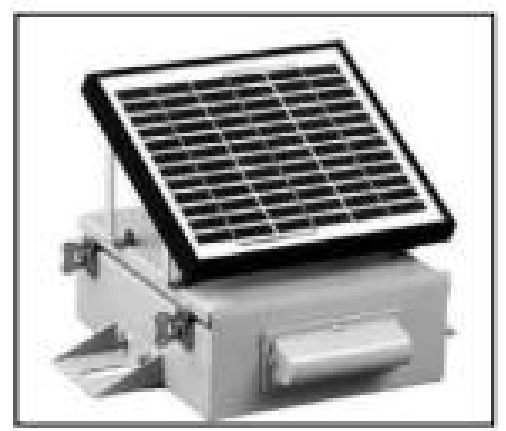

Fig. 2 Data Concentrator Unit

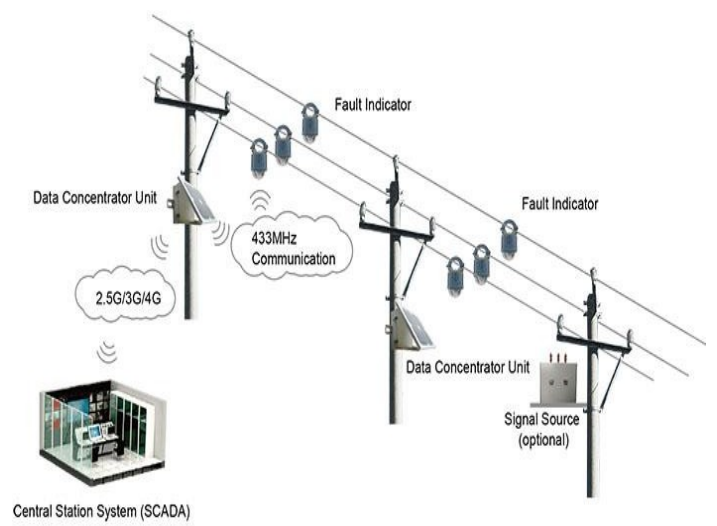

Fig. 3 Overhead FPI locating system monitoring

\section{Principle of working}

The main function of fault passage indicating system is to identify faults occurring in the downstream section from the point of its installation in the medium voltage system.
This is achieved by continuous monitoring of voltage presence and current flow in medium voltage line. Any increase in current along with absence of voltage is signaled by the equipment. Fault condition is indicated by flashing lights in FPI.

The recently developed versions include more circuitry such as memory and communication facility. Every fault indicator, earth-fault and short-circuit indicators, monitors the network constantly. As soon as a fault current higher than the trip value is detected, the fault will be indicated. To avoid wrong indications, most models of fault indicators are analyzing the measured fault signal with the help of a microcontroller [2].

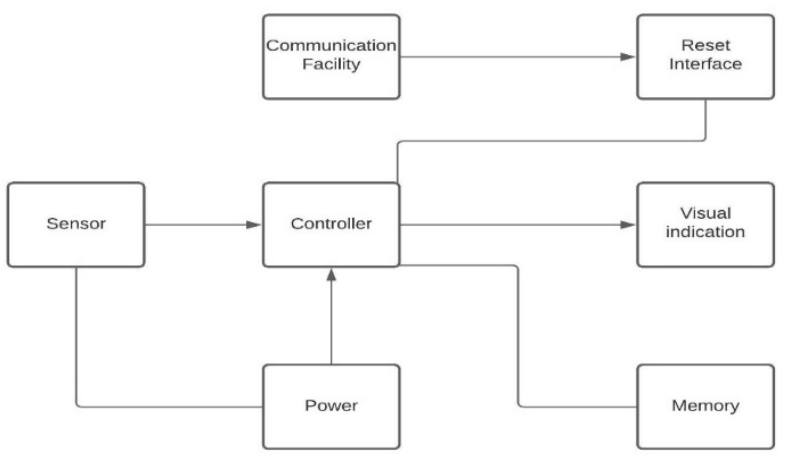

Fig. 4 Simplified block diagram of a fault passage indicator

\section{FPI in distribution networks}

Most of the distribution networks are radial with one source of supply or multiple sources of supply. Figure 1.18 shows two radial networks connected at ends with a normally open tie lines switch. Supposing a fault occurs at B3, circuit breaker CB2 would trip, as a result, supply is lost to B4, B5, B6, B1, B2 and B7. Generally, FPIs are not directional, they will indicate only whether the fault current is passed through it or not. When the fault is initiated, the operator should check for the circuit breakers tripped and fault indicators at every level. Here in this case, CB2 will trip and FPI at B3 will indicate the fault. The operator will now know the exact fault location. However, consider a case where in normally open (NO) switch is in closed condition and both the sources are supplying power to the loads. In this case, if a fault occurs and FPI is indicating the fault. Here in this case the operator doesn't know which source is the reason for the fault current because of non-directional indication of the fault. This type of scenario occurs when there is a fault between two substations. Therefore, directional FPIs might be required for closed loop/meshed networks. By which they can indicate whether the fault is 
upstream or downstream when viewed from the location of the FPI [28].

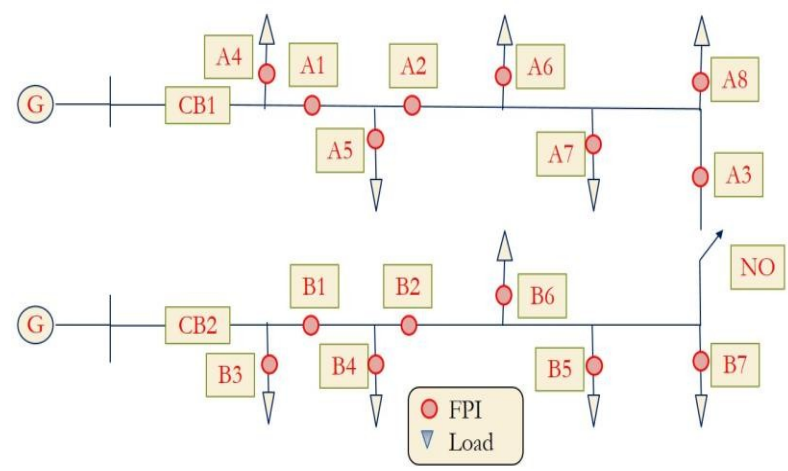

Fig. 5 Example of a Radial Distribution network with FPIs

\section{PROBLEM FORMULATION}

\section{Problem statement}

After thata fault occurs in the distribution network, the fault management process returns the system to the normal operation state. In general, a typical fault management process consists of three parts: locating the fault, isolating the fault, and restoring the power supply. Fault indicators provide information to accelerate the fault location process and the power supply restoration process. Therefore, the placement of fault indicator in the distribution network can significantly reduce interruption cost and improve reliability.

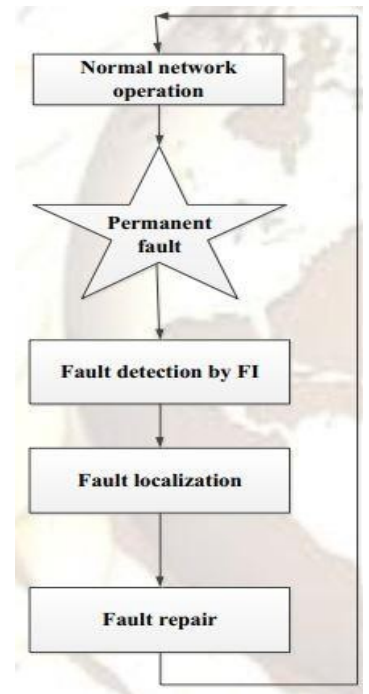

Fig. 6 Fault treatment process in network management [29]

It is necessary for the distribution utility to supply the electricity with acceptable degree of power quality for customers. Statistical studies indicate that due to radial structure of feeders and high failure rates in equipment, major number of faults occurs in the distribution networks. Fault detection is one of the important processes in network management for the guarantee of its security. During the past years, a few scenarios have been used in fault locating. In general, there are two methods for improving the reliability of distribution networks. The first method is to reduce the frequency of interruption and the second is to reduce the outage duration while fault occurs. Installation of FPIs in the primary feeders of distribution network is one of the ways to decrease the outage duration.

\section{Solution methodology}

The security and reliability and service continuity of power distribution system is very important, but it is violating with occurring faults. Fast clearing and isolation of different fault types are critical in maintaining a reliable power system operation and improve service continuity indexes.

According to our literature review, the principles of optimal placement of FPls can be classified into two distinct types. The first type includes direct optimization methods, where the reliability indices such as ENS (Energy Not Supplied). The second type is based on an indirect approach as the authors assemble auxiliary objective functions that are much simpler for optimization while, on the other hand, the obtained results are still located in the vicinity of the optimal solution [30]- [31]. In this method, a new combined economic objective function is assumed which must be optimized. Suggestion objective function is combination of three main part of benefit and disadvantage of finance such that show correct behavior of mutual effect between consumer and distribution companies. This objective function is composed four cases as follows:

$\checkmark \quad$ Energy not Supply (ENS)cost.

$\checkmark$ Operation cost and restoration cost.

$\checkmark$ Unsatisfied consumers cost.

$\checkmark$ FPI cost (buying \& installing).

a. EnergynotSupply (ENS)

'Energy not supplied' means the volume of energy to customers that is lost as a result of faults or failures on the network. This volume is an estimate of the energy that would have been supplied had the event not occurred taking into account the energy made available and/or actually supplied by the Licensee for the period of the fault event. In each interruption, restoration time depends on the type of fault and its location. This cause to be created addition cost which is forced on Power distribution companies. We introduce ENS by:

$$
C_{1}=C_{i} \sum_{t=1}^{n} P_{i} t_{i}
$$


Where:

$t_{i}=$ Interruptiontimeofit ${ }^{\text {th }}$ load.

$P_{i}=$ Amount of $\mathrm{i}^{\text {th }}$ load.

$n=$ Bus number.

$C_{i}=$ Cost of each kWh.

Most energy not supplied events are of a sufficiently short duration (less than 30 minutes) that the demand profile is unlikely to change. Over a period of time, it is expected that the effect of slight over- and underestimating energy not supplied on longer duration events would balance out.

\section{b- Operation cost and restoration cost}

Operations and Maintenance Costs mean the reasonable and necessary costs paid or incurred by the Recipient for maintaining and operating the System , including all reasonable expenses of management and repair and all of the expenses necessary to maintain and preserve the system in good repair and working order, and including all reasonable and necessary administrative costs of the recipient that are charged directly or apportioned to the operation of the system, such as salaries and wages of employees, overhead, taxes (if any), the cost of permits, licenses, and charges to operate the system and insurance premiums. Thus, operation cost and restoration cost are divided to two parts as follows:

- The cost of employers: The total amount of money that it costs a company to employ engineers and workers who work to restore the feeder., including pay, insurance, benefits...etc.

- Cost of equipment for restoration: When a piece of equipment is down, it will need restoration to continue the work it is supposed to accomplish. If the repair merely returns the equipment to its normal operating condition (which is the case most of the time), charge the cost of the repair tocompany

Thisis summarizedin one function:

$$
C_{2}=\sum_{i=1}^{n} \lambda_{i} l_{i} m_{i} \operatorname{Co}_{i} t_{i}+\sum_{i=1}^{n} m_{i} t_{i}+F
$$

Where:

$\lambda_{i}=$ Interruption rate peryear.

$l_{i}=$ Length of $\mathrm{i}^{\text {th }}$ branch.

$m_{i}=$ Number of employers.

$\mathrm{Co}_{i}=$ Hourly cost of each worker.

$t_{i}=$ Restoration time of $\mathrm{i}^{\text {th }}$ branch.

$F=$ cost of needed equipment for restoration. $n=$ Bus number. c- Unsatisfiedconsumers cost

Today's competitive business environment, merely satisfying is not enough to acquire long-term, repeat customers. A key aspect of managing customer relations is building lasting and positive relationships with customers. Acquiring new customer can cost up to 10 times as much as supporting an existing customer.

When any interruption is occurred for each consumer, they will be worried. Consequently, the electrical distribution company must be compensating effect of this interruption for each consumer. It has a standard fine cost for each hour for each consumer. UCC is introduced by:

Where:

$$
C_{3}=\sum_{j=1}^{m} \lambda_{i} l_{i} p_{i} t_{i}
$$

$\lambda_{i}=$ Interruption rate per year.

$l_{i}=$ Length of $\mathrm{i}^{\text {th }}$ branch.

$p_{i}=$ Active power consumption of each consumer.

$t_{i}=$ Restoration time of $i^{\text {th }}$ branch.

$m=$ Consumer number.

\section{d- FPI cost (buying \& instalation)}

FPls relevant costs are the major barriers in deploying FPIs in distribution networks. In this regard, a FPI deployment strategy is costeffective if it results in the minimum system cost including FPI deployment costs.

We assume different capital and installation costs can be considered as the same for different candidate locations regardless to the costs depend on several factors such as the network type, i.e., underground cables or overhead lines, and the required communication infrastructures, to name just a few.

The annual costs per FPI depend on the price of the FPI itself and the additional equipment needed. the cost of installation and maintenance, as well as the lifetime. These costs are derived from the following expression [32]:

$$
F P I_{\text {cost }}=\frac{F P I_{\text {price }}+F P_{\text {instal. }}}{F P I_{\text {age }}}+F P I_{\text {maint }} .
$$

The maintenance cost primarily includes the maintenance and rental of communication channels, while the installation cost is primarily related to the additional equipment needed for installation and deployment of FPIs, as well as for the purchase of certain software and other necessary equipment.

For simplification purpose, we introduce purchasing cost and installing cost in one grouped price as in (4):

$$
C_{4}=F P I_{\text {cost }}
$$

Equation (5) represents thepurchase and installation cost + repair group cost. 


\section{e- Used objective function}

Using a multiobjective genetic algorithm, we present an optimal fault passage indicator allocation for a fixed and variable number of them in PDN. We introduce a new combined objective function. This primary goal function is made up of four essential functions. The cost of various levels and types of loads has been assumed in each objective function element. Now, these four objective functions are grouped in:

$$
F_{o b j}=w_{1} C_{1}+w_{2} C_{2}+w_{3} C_{3}+w_{4} C_{4}
$$

Where $C_{1}, C_{2}, C_{3}, C_{4}$ are the previous functions in (1), (2), (3) and (4), respectively and the coefficients $w_{i}$ are weighting factors to indicate the importance of each term.

\section{THE GENETIC ALGORITHM}

Inspired by the collective behavior of swarms in nature, researchers have observed such behaviors of animals, plants, or humans, analyzed the driving force behind the phenomena, and then proposed various types of algorithms [33]. Some of the most recent ones are Glowworm Swarm Optimization (GSO), Bees Algorithm (BA), Artificial Bee Colony $(\mathrm{ABC})$ algorithm, Bat Algorithm (BA), Firefly Algorithm (FA), Cuckoo Search (CS) algorithm, Cuckoo Optimization Algorithm (COA), Grey Wolf Optimizer (GWO). Dolphin Echolocation (DE, Hunting Search (HS), and Fruit Fly Optimization Algorithm (FFOA) [34].

The genetic algorithm

Genetic algorithms represent one branch of the field of study called evolutionary computation [35], in that they imitate the biological processes of reproduction and natural selection to solve for the 'fittest' solutions [36]. Like in evolution, many of a genetic algorithm' processes are stochastic. However, this optimization technique allows one to set the level of randomization and the level of control [36]. These algorithms are far more powerful and efficient than random search and exhaustive search algorithms [35], yet require no extra information about the given problem. This feature allows them to find solutions to problems that other optimization methods cannot handle due to a lack of continuity, derivatives, linearity, or other features.

The process of natural selection starts with the selection of fittest individuals from a population. They produce offspring which inherit the characteristics of the parents and will be added to the next generation. If parents have better fitness, their offspring will be better than parents and have a better chance at surviving. This process keeps on iterating and at the end, a generation with the fittest individuals will be found. This notion can be applied for a search problem. We consider a set of solutions for a problem and select the set of best ones out of them [37].

\section{A Simple Genetic Algorithm procedure}

Given a clearly defined problem to be solved and a bit-string representation for candidate solutions, the simple GA works as follows:

$\checkmark$ Start with a randomly generated population of $\mathrm{N}$ L-bit chromosomes (candidate solutions to a problem).

$\checkmark$ Calculate the fitness $F(x)$ of each chromosome $\mathrm{x}$ in the population.

$\checkmark \quad$ Repeat the following steps (a)-(c)until $\mathrm{N}$ offspring have been created:

a- Select a pair of parent chromosomes from the current population, with the probability of selection being an increasing function of fitness. Selection is done "with replacement". Meaning that the same chromosome can be selected more than once to become a parent.

b- With probability $\mathrm{P}_{\mathrm{C}}$ (the crossover probability), cross over the pair at a randomlychosen point (chosen with uniform probability) to form two offspring. If no crossover takes place, form two offspring that are exact copies of their respective parents.

c- Mutate the two offspring at each locus with probability $\mathrm{Pm}$ (the mutation probability), and place the resulting chromosomes in the new population.

$\checkmark$ Replace the current population with the new population.

$\checkmark \quad$ Go to step 2.

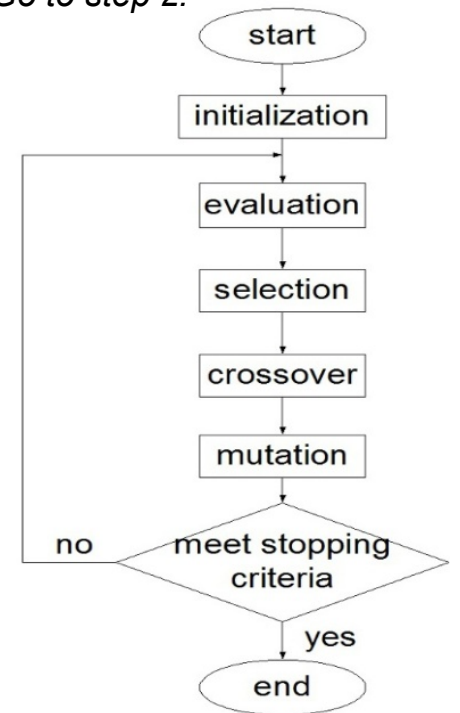

Fig. 7 Flowchart of genetic algorithm [38] 


\section{RESULTS AND DISCUSSIONS}

The optimal FPI allocation is a combinatorial multi-objective optimization problem that determines the number of FPls and the best placement in a given power distribution system. In this case, FPI locations are represented by binary decision variables. $\mathrm{N}$ bits $(0,1)$ have assumed for allocating of FPIs with attention to fitness function where each bit represents a branch in power distribution network. Ifthe value of $i^{\text {th }}$ bit is 1 , the $i^{\text {th }}$ branch has an FPI, otherwise it does not, and it is not included inthenetworkcomputations.

In this section, the proposed objective function is applied to a test network IEEE 9 bus radialdistributionnetworkand then we extend our study on IEEE 33.

\section{Case study 1}

First, the objective functionwas tested for a 9bus system. This test system has been used inprevious works [39]. The parameters of this system are shown in table 1.

Table 1 IEEE 9-bus System data

\begin{tabular}{|c|c|c|c|c|c|}
\hline $\begin{array}{l}\text { Load } \\
\text { point }\end{array}$ & $\left|\begin{array}{c}\text { Amount } \\
\text { of Load } \\
\mathrm{Pi}[\mathrm{kW}]\end{array}\right|$ & $\begin{array}{c}\text { Interruption } \\
\text { time of } \\
\text { ithload } t_{i}\end{array}$ & $\begin{array}{c}\text { Interruption } \\
\text { rate per year } \lambda_{i} \\
{[f / y]}\end{array}$ & $\begin{array}{c}\text { Length of } \\
\text { branchli } \\
{[\mathrm{km}]}\end{array}$ & $\begin{array}{l}\text { Costumer } \\
\text { Number }\end{array}$ \\
\hline 1 & 220 & 0.5 & 0.0195 & 18 & 137 \\
\hline 2 & 150 & 0.5 & 0.0026 & 0.5 & 126 \\
\hline 3 & 180 & 0.5 & 0.0026 & 0.7 & 130 \\
\hline 4 & 40 & 0.5 & 0.0130 & 0.3 & 20 \\
\hline 5 & 110 & 0.5 & 0.0325 & 0.7 & 50 \\
\hline 6 & 50 & 0.5 & 0.0650 & 0.7 & 30 \\
\hline 7 & 50 & 0.5 & 0.0065 & 0.6 & 35 \\
\hline 8 & 150 & 0.5 & 0.0091 & 0.5 & 170 \\
\hline 9 & 110 & 0.5 & 0.0572 & 0.65 & 100 \\
\hline
\end{tabular}

Interruption time has been assumed to be the same value (0.5) according to [30] and [40]. The costof each kWh Cils 0.5 USD provided from [41]. Accordingto [41],Flcost(buying\& installing)hasbeencalculated to be 733.3 USD.

Otherparameterswerecarefullybroughtandapp roximatedaccordingtotheoriginalnetwork from [25], [30], [42] and [43]. The numberofworkers hasbeenassumed

tobe2workerson eachbranch. Theresultsofoursimulationare shown in Fig. 8.

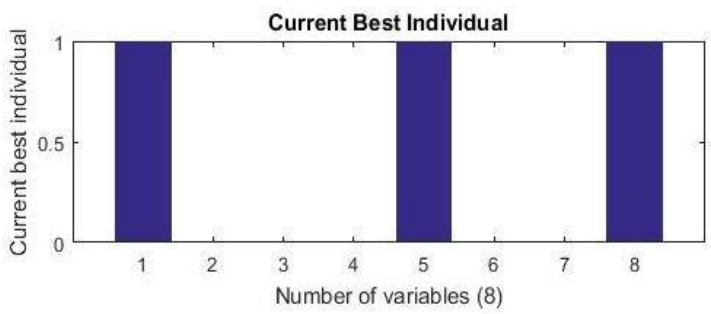

Fig. 8 GA Bestindividual

The results of the optimization suggest placing $3 \mathrm{FPls}$ at buses 1, 5 and 8. In order to validate our results, we created an approximate implementation of an FPlusing MATLAB-SIMULINK based on the block diagram in Fig. 4.

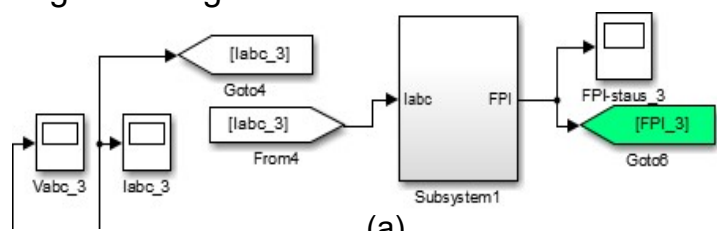

(a)

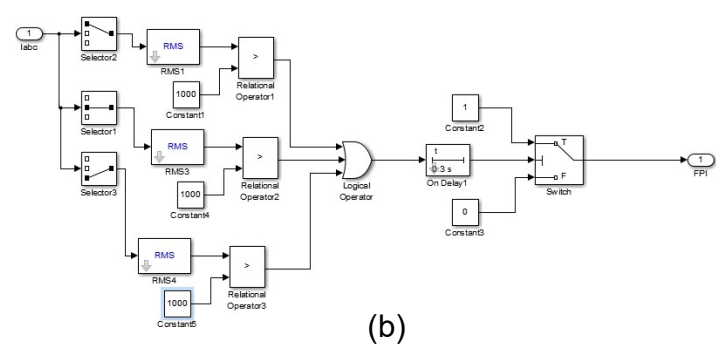

Fig. 9 MATLAB SIMULINK FPI Model

(a) FPI model (b) Sub-system

The FPI models have been placed at buses 1,5 and 8 as suggested by the optimization results. The system is shown in Fig. 10.

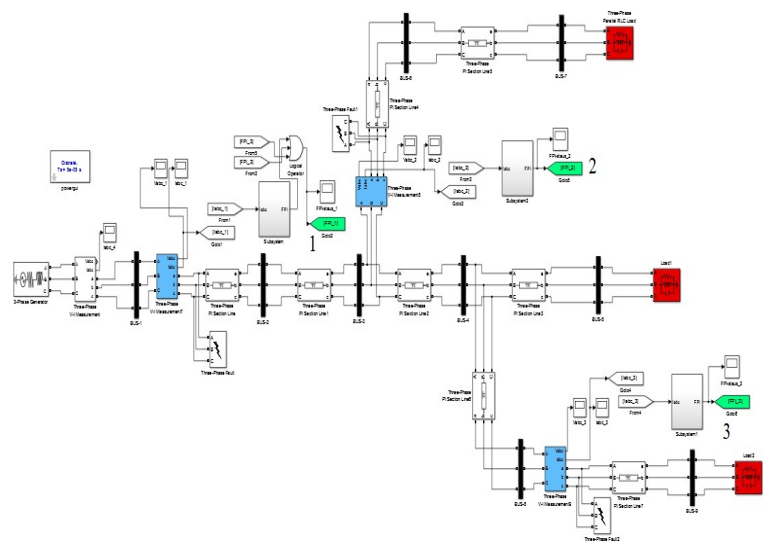

Fig. 10 SIMULINK FPI placement in 9-bus system (FPls are shown in green)

By creating a single phase to ground (A-G) fault at branch 1, as seen from Fig. 11, phase A has very high current due to the fault. Only FPI (1) is tripped because our model is unidirectional andcannotdetect upstreamfaults 
as seen infigures 12 and 13 .

(A-G) faults at branch $5 \& 8$ will trip FPls 2 and 3 , respectively (fig. 14) and FPI 1 will beautomatically triggered. This is because it is allocated at $1^{\text {st }}$ bus on main feeder which detects allSCs of 9-bus system which indicates 2 possible suspected locations each.

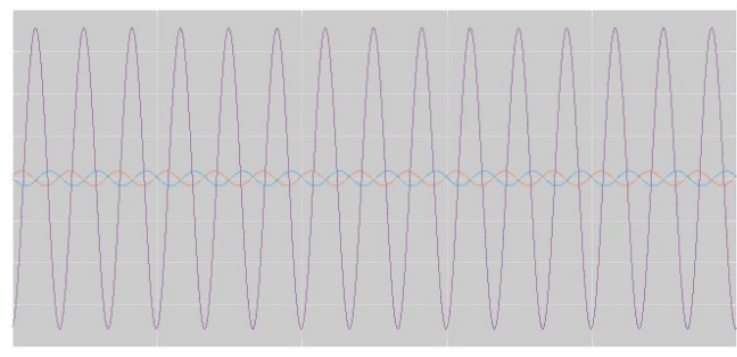

Fig. 11 Branch 1 FPI current scope

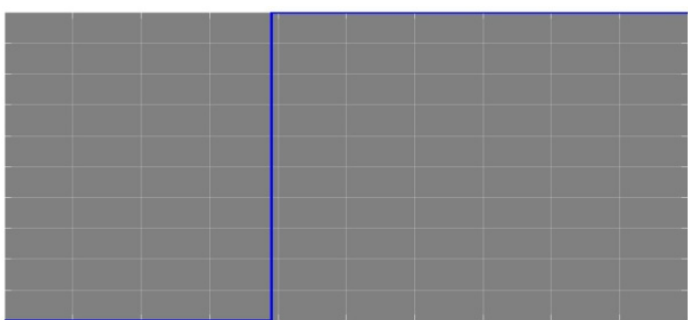

Fig. 12 FPI 1 response scope

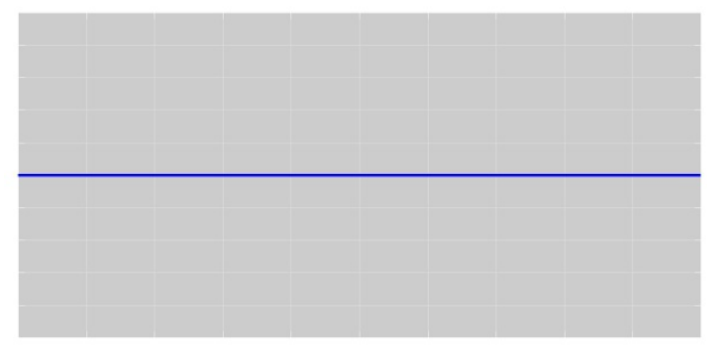

Fig. 13 FPI 2 \& 3 responsescope

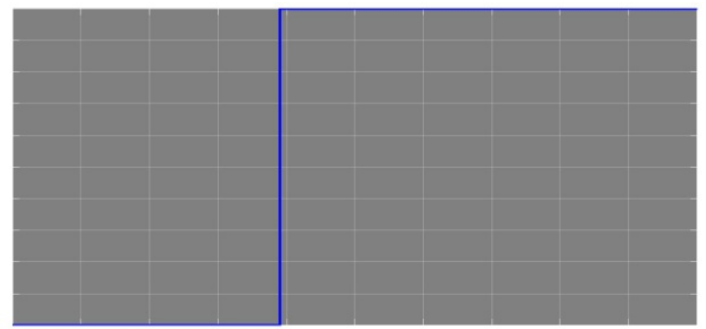

Fig. $14 \mathrm{FPI}(5)$ and $\mathrm{FPI}(1)$ response scope with a fault at bus 5 .

\section{Case Study 2}

In this section, we extend our placement study to the 33-bus system as shown in Fig 15 and its data are given in table 2 [44].

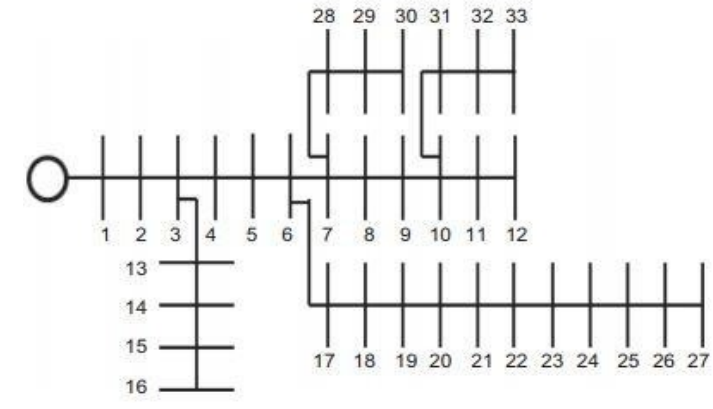

Fig. 15 IEEE 33-bus radial distribution system

Table 2 IEEE 33-bus System data

\begin{tabular}{|c|c|c|c|c|c|}
\hline $\begin{array}{l}\text { Load } \\
\text { point }\end{array}$ & $\begin{array}{l}\text { Amount } \\
\text { of Load } \\
\mathrm{Pi}[\mathrm{kW}]\end{array}$ & $\begin{array}{l}\text { Interruption } \\
\text { time of } \\
\text { ithload } t_{i}\end{array}$ & $\begin{array}{c}\text { Interruption } \\
\text { rate per } \\
\text { year } \lambda_{i} \\
{[f / y]}\end{array}$ & $\begin{array}{l}\text { Length } \\
\text { of } \\
\text { branch } \\
\text { li }[\mathrm{km}]\end{array}$ & $\begin{array}{l}\text { Costumer } \\
\text { Number }\end{array}$ \\
\hline 1 & 100 & 0.5 & 0.295 & 1 & 135 \\
\hline 2 & 90 & 0.5 & 0.305 & 1 & 137 \\
\hline 3 & 120 & 0.5 & 0.295 & 1 & 149 \\
\hline 4 & 60 & 0.5 & 0.308 & 1 & 57 \\
\hline 5 & 60 & 0.5 & 0.305 & 1 & 60 \\
\hline 6 & 200 & 0.5 & 0.308 & 1 & 236 \\
\hline 7 & 200 & 0.5 & 0.305 & 1 & 203 \\
\hline 8 & 60 & 0.5 & 0.130 & 1 & 55 \\
\hline 9 & 60 & 0.5 & 0.230 & 1 & 57 \\
\hline 10 & 45 & 0.5 & 0.234 & 1 & 49 \\
\hline 11 & 60 & 0.5 & 0.298 & 1 & 66 \\
\hline 12 & 60 & 0.5 & 0.295 & 1 & 60 \\
\hline 13 & 120 & 0.5 & 0.285 & 1 & 142 \\
\hline 14 & 60 & 0.5 & 0.295 & 1 & 57 \\
\hline 15 & 60 & 0.5 & 0.285 & 1 & 57 \\
\hline 16 & 60 & 0.5 & 0.295 & 1 & 57 \\
\hline 17 & 90 & 0.5 & 0.295 & 1 & 130 \\
\hline 18 & 90 & 0.5 & 0.311 & 1 & 133 \\
\hline 19 & 90 & 0.5 & 0.301 & 1 & 145 \\
\hline 20 & 90 & 0.5 & 0.311 & 1 & 129 \\
\hline 21 & 90 & 0.5 & 0.311 & 1 & 137 \\
\hline 22 & 90 & 0.5 & 0.301 & 1 & 137 \\
\hline 23 & 420 & 0.5 & 0.311 & 1 & 315 \\
\hline 24 & 420 & 0.5 & 0.311 & 1 & 340 \\
\hline 25 & 60 & 0.5 & 0.301 & 1 & 50 \\
\hline 26 & 60 & 0.5 & 0.189 & 1 & 50 \\
\hline 27 & 60 & 0.5 & 0.192 & 1 & 57 \\
\hline 28 & 120 & 0.5 & 0.179 & 1 & 149 \\
\hline 29 & 200 & 0.5 & 0.192 & 1 & 236 \\
\hline 30 & 150 & 0.5 & 0.202 & 1 & 176 \\
\hline 31 & 210 & 0.5 & 0.192 & 1 & 150 \\
\hline
\end{tabular}




\begin{tabular}{|l|l|l|l|l|l|}
\hline 32 & 60 & 0.5 & 0.302 & 1 & 56 \\
\hline 33 & 60 & 0.5 & 0.302 & 1 & 57 \\
\hline
\end{tabular}

Theresults of the best GA individual are shown in Fig. 16.

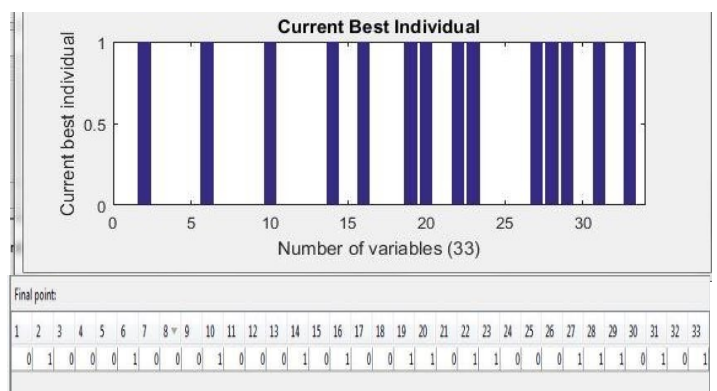

Fig. 16 GA Best individual for simulation of 33-bus system with FPI placement positions

The results suggest placing $14 \mathrm{FPIs}$ in this distribution system. As shown in Fig. 16, these must be placed at buses: 2,6,10, $14,16,19,20,22,23,27,28,29,31$ and 33. Again, the system is simulated with the FPls placed as indicated.

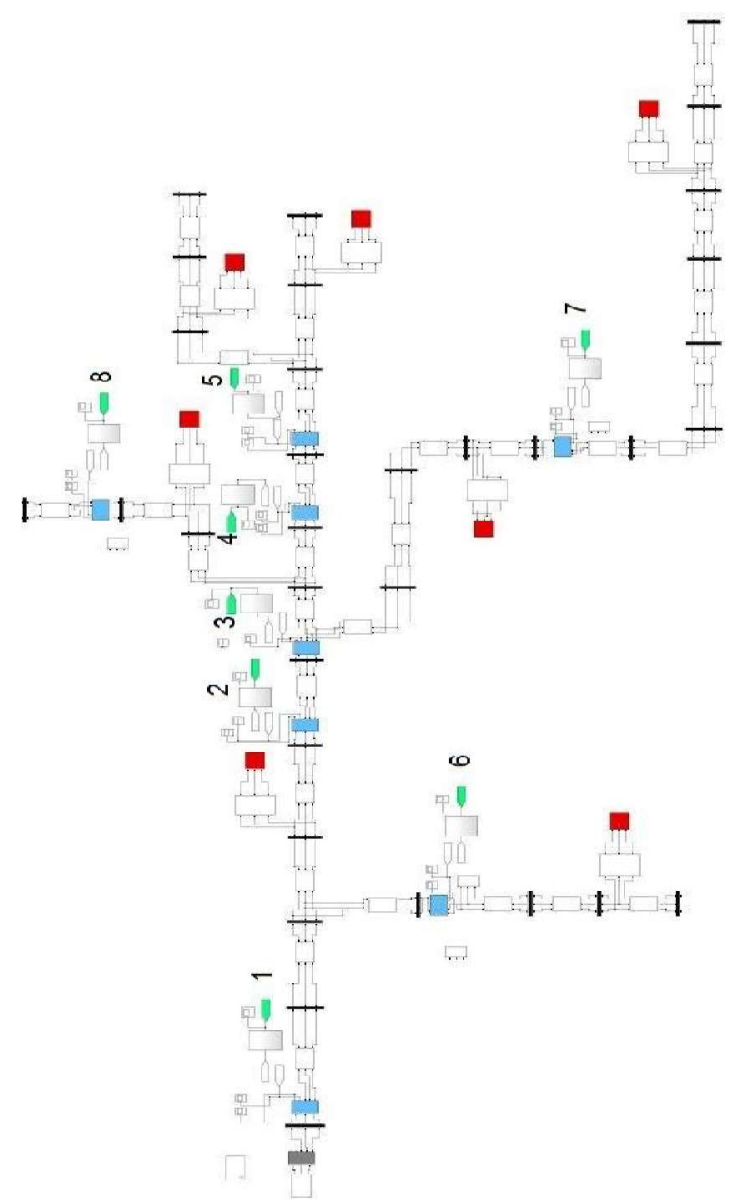

Fig. 17 SIMULINK FPI placement in 33-bus system (FPls are shown in green)

It should be noticed that only 9 FPls have been placed for reasons to be indicated later.
Becauseoursystemis relatively large, wecan'tdiscuss all fault possibilities. Instead, wewillassume 3scenariosoffaults and discuss them.FPlarenumbered startingfrom themainfeeder(bussesfrom 1to12)andthenfromlaterals.

$\checkmark$ If a (A-G)faultis atbranch3triggers onlyFPI(1)which similar to the 9-bus case study

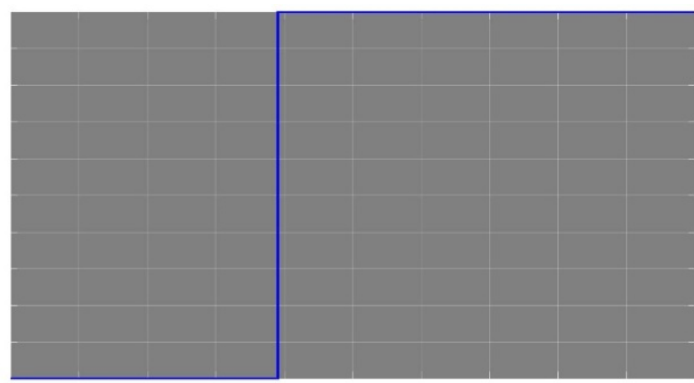

(a)

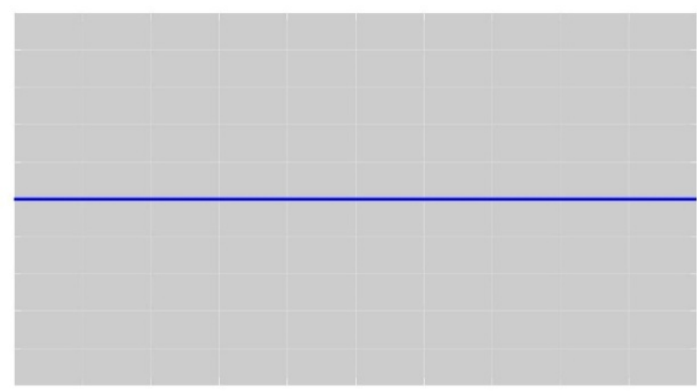

(b)

Fig. 18 (a) $\mathrm{FPI}(1)$ (b) rest of FPIs

$\checkmark$ Faultoccurringonbus24(branch24)trig gersFPIs1-7-2-

3sincetherestofFPIsareoutof rangeof detection whichindicates 2 possible suspected locations(branch 25-27).

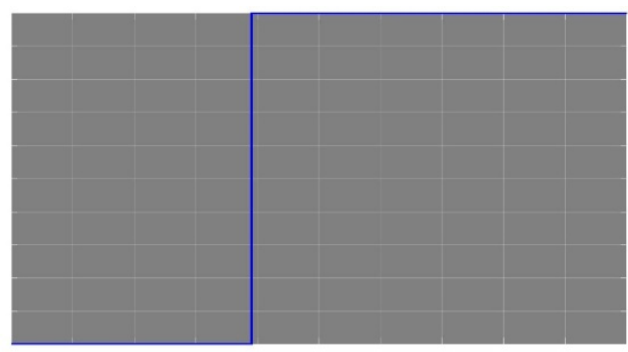

(a)

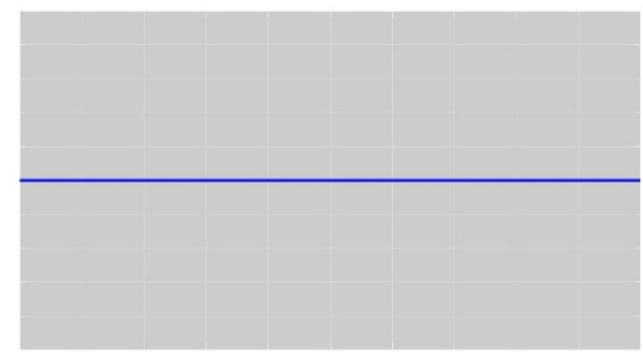


(b)

Fig. 19 (a) FPI (1-7-2-3) (b) rest of FPI

$\checkmark$ If a Fault isat bus31 hasturned onFPIs $8,1,2 \& 3$ which issamecaseas the previous situation.

$\checkmark \quad$ We removed FPIs at the end busses $(12-16 \& 33)$ since the FPI model is uni-directional and thereisno needof placingthemat theend.So ouroptimum numberhasbeenreduced to11 FPIs

$\checkmark$ Any Fault occurringinthe 33-bus system can be detected by at least 2 FPls which reduces faultdetectionrange.

\section{CONCLUSION}

In this paper, the problem of allocating a minimum number of faulted-circuit indicators inorder to detect faults occurring along a distribution feederhas been addressed. Theoptimal number is found for two different systems using an optimization technique and testedwithan approximated FPImodel. The problem has been modeled using a multiobjectivefunctiontobeminimizedbyGA. The results were testedon two state of art distribution systems: IEEE 9-bus and 33busradialdistributionnetworks. The results were satisfactory as the number of FPls to be placed was in the two cases less than the total number of buses. This suggests that less number of FPls need to be deployed to for the same fault location accuracy. This is economically a very interesting result as in practical situations; the systems are so large that placing an FPI at each bus would mean huge investment.

\section{References}

[1] AbdelmadjidRecioui, Hamid Bentarzi. Optimizing and Measuring Smart Grid Operation and Control. IGI Global, 2021.

[2] K. Mustapha and L. A. Mounir, "Design and Implementation of an Overhead Fault Passage Indicator for Medium Voltage Network, Master project report,"Institute of Electrical and Electronic Engineering, Boumerdes, 2020.

[3] M. E. El-Hawary, "POWER GENERATION AND THE SYNCHRONOUS MACHINE" in Electrical Energy Systems, Boca Raton, Florida, THE ELECTRIC POWER ENGINEERING Series, 2000, p. 77

[4] K.Daware,"Electrical Easy,"2014. https://www.electricaleasy.com/2016/01/electri cal-power-grid-structure-working.html..

[5] F. Chan, "ELECTRIC POWER DISTRIBUTION SYSTEMS," ELECTRICALENGINEERING-

Vol.III,HongKongSAR, China, the globalEncyclopediaof LifeSupportSystems (EOLSS), 2009, p. VOL3.

[6] Westinghouse Electric Corporation, "Electric Utility Engineering," in distribution systems,
Vol. 3, Pittsburgh, Pennsylvania. USA, Westinghouse Electric Corporation, 1965.

[7] R. Das, "DETERMINING THE LOCATIONS OF FAULTS," National Library of Canada, Saskatoon, Canada, 1998.

[8] ARecioui. Home Load-Side Management in Smart Grids Using Global Optimization In: Research Anthology on Multi-Industry Uses of Genetic Programming and Algorithms, IGI Global, 2021, p. 1017-1052.

[9] A Ouadi, H Bentarzi and ARecioui. Optimal multiobjective design of digital filters using taguchi optimization technique. J. of Elec. Eng. 2014; 65(1), De Gruyter Poland.

[10] A Recioui and M Bouaraki. Optimal placement of power factor correction capacitors in power systems using Teaching Learning Based Optimization. Alg. J. of Sig. \& Sys. 2017; 2(2), 102-109.

[11] A Recioui. Capacity Optimization of MIMO Systems Involving Conformal Antenna Arrays using a Search Group Algorithm. Alg. J. of Sig. \& Sys. 2020; 5(4), 209-214.

[12] B. R. and . J. S, in Optimal switching device placement, IEEE Trans. Power Del., vol.11, Jul. 1996, p. 1646-1651.

[13] T. J. H and . L. Y. H, in A novel ACS-based optimum switch relocation method, IEEE Trans. Power Syst, vol. 18, no. 1, Feb 2003, p.113-120.

[14] C, Chen; C.,Lin; H. , Chuang; C. , Li; M. , Huang; C, Hu, "Optimal placement of lineswitches for distribution automation systems using immune algorithm," IEEE Trans. PowerSyst, Vols. 21, no. 3, p. 12091217, Aug. 2006.

[15] Fotuhi-Firuzabad, A. Moradi, "Optimal switch placement in distribution systems usingtrinaryparticle swarm optimizationalgorithm," IEEE Trans.Power Del,Vols.vol. 23, no.1, p. 271-279,Jan 2008.

[16] J. R. Bezerra, G. CordeiroBarroso, R. P. SaraivaLeao, R. Furtado Sampaio, "Multiobjective optimization algorithm for switch placement in radial power distributionnetworks,"IEEE Trans. PowerDel,vol. 30 no.2, p. 545-552, Apr.2015.

[17] P. M. S, Carvalho; L. A. F. M, Ferreira; A, J, "A decomposition approach to optimalremote controlled switch allocation in distribution systems," IEEE Trans. Power Del, Vols.20,no. 2, p. 1031-1036, Apr. 2005.

[18] Lu, J. H. Teng and C. N., "Feeder switch relocation for customer interruption costsminimization,"EEETrans.

PowerDel,Vols. 17, no.1, p. 254-259, Jan. 2002.

[19] I. Lim; T. S, Sidhu; M. S, Choi; S. J, Lee, "An optimal composition and placement ofautomaticswitches in DAS,"IEEE Trans. PowerDel., Vols. 28, no. 3,pp, p. 14741482,July2013.

[20] A, Abiri-Jahromi; M, Fotuhi-Firuzabad; M, Parvania, "Optimized sectionalizing switchplacement strategy in distribution systems," IEEE Trans. Power Del, Vols. 27, no. 1, p.362-370, Jan. 2012.

[21] M.Izadi, M. Farajollahi,A. SafdarianandM. Fotuhi-Firuzabad,"A multistage MILPbasedmodel ofremotecontrolswitch into distributionnetworks," in inProc.2016/nt. 
Conf.onProb.Methods

Syst(PMAPS),Beijing,2016.

[22] M. Farajollahi, M. Fotuhi-Firuzabad and A. Safdarian "Optimal Placement ofSectionalizing SwitchConsidering Switch Malfunction Probability," IEEE Trans. on SmartGrid,Vols.PP, no. 99, pp. 1-1, 2017.

[23] A. Shahsavari, A. Fereidunian, M. Mazhari, "A joint automatic and manual switchplacement within distribution systems considering operational probabilities

controlsequences,"Int. trans.

of

Elect.EnergySyst,Vols. 25, no.11, p. 27452768, 2015.

[24] D.P.Cong, "Optimization of fault indicators placement with dispersed generation insertion,"IEEE Power Eng. Soc. General Meeting,p. 355-362, 2005.

[25]H. Falaghi, "Fault indicators effects on distribution reliability indices," in Proc.18thInt.Conf. ElectricityDistribution, 2005.

[26] D. Almeida, "Optimal placement of faulted circuit indicators in power distributionsystems," Elsevier, Electric Power Systems Research, Vols. 81, no.2, pp. 669706,2011.

[27] C.G.d.Miguel, .D.R.Tom and D. Johan, "Implementation of a Digital Directional Fault, "Research Gate, Belgium,TheNetherlands, 2015.

[28] V. C. R. B, "Outage Management System with Fault Passage," Indian Institute of Technology Hyderabad, India, 2015.

[29] Reza Baradaran Hendi, Seyed-Jalal, SeyedSheneva , Majid Gandomkar, "Electrical Distribution System Reliability Improvement by Optimal Placement of Fault Indicatorsusing Immune Algorithm," International Journal of Engineering Research andApplications(IJERA), vol. 2, no.2, pp. 1383-1390, Mar-Apr 2012.

[30] D. B. de Souza, A. F. de Assis, I. N. da Silva, and W. F. Usida, "Efficient fuzzyapproach for allocating fault indicators in power distribution lines," in EEE TransmissionandDistributionConferenceandE xposition,LatinAmerica,pp.1-6,August 2008.

[31] W. F. Usida, D. V. Coury, R. A. Flauzino and I. N. da Silva, "Efficient Placement ofFault Indicators in an Actual Distribution System Using Evolutionary Computing," IEEETransaction on Power Systems, vol. 27, no. 4, pp. 1841-1849, no. 4, pp. 18411849,November2014.

[32] Q. o. S. T. F. Electricity Working Group, "Third Benchmarking Report on Quality ofElectricitySupply,"inCouncilof European Energy Regulators,Bruxelles,2005

[33] X.Shan,L.KangandS. Pei-Liang,"Modified Bat Algorithm Based on Lévy Flight and Opposition Based Learning,"Hindawi PublishingCorporation, China, 2016.

[34] A. W. Mohd Nadhir , N.-M. Samia and A. Adham, "A Comprehensive Review of Swarm," Plos One, vol. 3, pp. 15-25, 2015.

[35] A. RECIOUI, A. AZRAR, "Use of Genetic Algorithms in Linear and Planar Array Synthesis using Schelkunoff Method", Microwave and Optical Technology Letters, Vol. 49, issue 7, July 2007.
[36] A. RECIOUI et al., "Synthesis of Linear Arrays with Sidelobe Level Reduction Constraint using Genetic Algorithms", International Journal of Microwave and Optical Technology, Vol. 3, No. 5, November 2008.

[37] A. RECIOUI and H. BENTARZI, "Genetic Algorithm based MIMO capacity enhancement in spatially correlated channels including Mutual Coupling", Wireless Personal communications, Springer, Volume 63, Number 3, 2012, pages: 689-701. DOI: 10.1007/s11277-010-0159-5.

[38] A. Recioui, Application of a Hybrid TaguchiGenetic Algorithm to the Multiobjective Design Optimization of Yagi-Uda Antennas, Wireless Personal Communications, Volume 71, Issue 2, 2013, pp 1403-1420

[39] J. S. Rahman Dashti, "Fault Indicator Allocation in Power Distribution Network for Fault Indicator Allocation in Power Distribution Network for," in The International Conference on Advanced Power System Automation and Protection, Iran, 2011.

[40] Č. Zeljković, P. Mršić, Đ. Lekić, B. Erceg, P. Matić, S. Zubić, and P. Balcerek, "Performance Assessment of Fault Locators and Fault Passage Indicators in Distribution Networks by the Non-Sequential Monte Carlo Simulation," 2018 International Symposium on Industrial Electronics (INDEL), Banja Luka, Bosnia and Herzegovina, pp. 1-7, 1-3 Nov. 2018.

[41] P. Mršić, Č. Zeljković, Đ. Lekić, B. Erceg, P. Matić, S. Zubić, and P. Balcerek, "Minimization of Power Interruption Time in MV Distribution Networks with Fault Locators Based on Optimal Placement of Fault Passage Indicators," 2018 International Symposium on Industrial Electronics (INDEL), Banja Luka, Bosnia and Herzegovina, pp. 1-7, 1-3 Nov. 2018.

[42] Vidya Sagar, and P.V.N. Prasad, "Optimum location of $\mathrm{FPI}$ on radial feeder based on reliability and cost indices", 17th National Power System Conference at IIT(BHU), Varanasi, 12th -14th December, 2012

[43]

J.C.Leon.and.M.J.Ray.JhairS.Acosta,"Optimal Multi-Scenario,Multi-Objective of Fault Indicators in Electrical Distribution Systems using a Mixed-Integer Linear Programming Model", IEEE Transactions on Smart Grid,2018.

[44] C. Loki and D. B. Prakash, "Optimal siting of capacitors in radial distribution networkusingWhale Optimization Algorithm," Alexandria Engineering Journal, no. Karnataka560019, India, pp. 4-11,2016. 